\title{
A Flexible Design of Individual Training of English Skills Based on the Web
}

\author{
Sun Dongling \\ School of Foreign Languages, Changchun Inst. of Technol., Changchun, China \\ CCIT \\ Changchun, China \\ 1229058230@qq.com
}

\begin{abstract}
The thesis is on the basis of a progressive study of the flexible application of the web,the Personal Web Page. It is widely accepted that technology is a device to promote the development of education and the scholars and teachers have devoted themselves to modern educational technology from different angles but there are also some problems arsing. The thesis first gives a brief introduction of the present application conditions of the Web technology, and points out the problems . Then the design of individual training of English skills based on the web,the Personal Web Page in this progressive study is introduced. The theoretical bases and research devices are also argued. This progressive study aims to exploit the Web technology to innovatively enrich the ways, methods and devices of improvement of the students' English skills, and the scientificity, practicability, efficiency and popularization of the study design will be given further argued with the progress of the study.
\end{abstract}

Keywords-flexible design; individual training; platform; research devices; the web

\section{INTRODUCTION}

Since the $20^{\text {th }}$ century, our country has been experiencing the fastest development of Internet, and the Web technology has brought a revolution to education industry. In this specific historical period of information explosion, Web technology can even play a leading role in education. Since the $20^{\text {th }}$ century, the exploitation of web technology in education field has been prevailing much. Compared with traditional education, informationized education is characterized glaringly with multimedia-supported materials, individual training, open design, autonomous study, cooperative tasks, various environment, and automatic evaluation. Integrating Web technology with students' English skills training can emphasize the important points, solving the difficult points.

\section{EXISTING PROBLEMS OF THE APPLICATION OF WEB TECHNOLOGY IN TEACHING}

\section{A. Campus Net and teaching platform have limitations in cultivating students' English skills}

England and America are the countries which experience the earlier development of distant education. $\mathrm{Bb}$ teaching platform has been introduced into some colleges to serve teaching, and some college English teachers try to make use of it to improve students' English skills. But the teaching platform doesn't have the function that teachers and students can make an instant communication, in addition, such a teaching platform has limited registration, and as far as the whole college is concerned, it can not be widely used. That's to say not all the teachers who want to use it can have a chance.

Campus Net can not be used according to the teacher's inclination. Because campus Net is managed by the college authority, the teacher cannot open his (her) own column which more conform to individual teaching concept. Therefore, in present situation, Campus net and the teaching platform which has been used by college English teachers in different degree don't help much in the instant communication between teachers and students, teachers' individual instruction for students for the improvement of students' English skill.

B. The exploitation of personal Web pages by teachers who want to improve students' English skills lacks in depth and width

It is quite common for the college English teachers to use personal Web pages to communicate with students because of the limitation of campus Net and $\mathrm{Bb}$ teaching platform. Personal Web pages depend on the whole Web system which is almost always available, and all the people can make a registration at any time. Email box and personal Q-zone can be freely used. But many teachers mainly send and receive emails and talk with students via QQ to make awareness of students' ideological tendency and their needs. Thus the exploitation of personal Web pages lacks in depth and width, and it is not systematic, normative and regular. Therefore the deep exploration of personal pages should be done. 


\section{THE DESIGN OF INDIVIDUAL TRAINING OF ENGLISH SKILLS BASED ON THE PERSONAL WEB PAGE}

Since the middle of 1990s, autonomous study and individual training has been more and more valued. The development of Web technology provides wide space for autonomous study and individual training. Given the limitation of campus Net and teaching blackboard, the present researcher makes a deep exploitation of personal Web pages for the individual training of the students in English skills.

\section{A. The framework of the study}

School education decides the limitation of class teaching, and it is the teacher's task to work out how to continue with the training of students' English skill beyond class time. In the 21 st century with the rapid development of Web technology and the increase of students' users, teachers have more convenient conditions and media for their use. Teachers and students all have their individual traits. Every teacher has his(her) personal characters and styles and every student has his (her)studying base and requirements. The present study aims to how teachers exert their individual advantages to improve students' English skills according to students' characteristics and requirements via personal Web pages. personal Web pages are popular, convenient, and flexible, and the present study makes a deep use of it to serve for the training of students' English skills: on one hand, the study tries to make the exploitation of Web page conform to the individual differences of the students and the exclusive styles of the teachers, on the other hand, the training must follow the theories of language acquisition and education. The present study goes on with five Web platforms carried in the Web pages to have individual training of the students in English skills: the management and contact platform, the information platform, the communication platform, resources platform, submission platform.

\section{I) The management and contact platform}

The students of every teacher may vary in class, grade, subject, so in order to instruct, inform and contact the individual student conveniently and improve efficiency, it is necessary to form a management and contact platform. The concrete process is to add new general classifications on QQ home page, namely, to classify the registered students users on the teacher's personal Web page.

II) The information platform

On Q-zone homepage, the first column is the owner's words, which can be adapted for the column with notification , thus the teacher can send notice for all the students, and the information platform is formed. The various tasks and training programs sent to the other platform by the teacher can be informed to the students on this platform.

\section{III) The communication platform}

The message board in Q-zone can be made as a communication Platform on which the instant discussion, communication and feedback can be made between teachers and students, students and students. Message board is flexible. The users can make instant communication or leave messages. Teachers can know the individual student' studying, thought, and needs, therefore have timely communication, give individual instruction and solve the practical problems.

\section{IV) The resources platform}

QQ diary can be further classified, and new classifying choices can be made. Thus QQ diary can be made as a recourses platform on which various materials can be put on it under different items. The added choice column can be marked as: activities files, texts guides, cultural salon, vocabulary enlargement, class videos, assignment exhibition, English bands, TOEFL etc.

\section{V) The submission platform}

The students can submit assignment via QQ-box, so QQ-box becomes a submission platform. Certainly the students can also make a submission via off-line files and online files. The five Web platforms are attached to the personal Web pages, and they are independent and interrelated. The subjects of the study are the students of the present researcher. The study will argue the scientificity, practicability, efficiency and popularization of the students' individual training in English skills based on personal Web pages, through the application research by collecting data and various materials.

\section{B. The emphasis of the study}

The study emphasizes on the deep application of personal Web pages, and undergoes a scientific, reasonable, and efficient design and practice to have a individual training of students in English skills. At the same time the study tries to make the abnormal English skills training into a normal, scientific, systematic, and regular process.

\section{The difficult point of the study}

Personal Web pages are already widely used, but the deep application of it in teaching is less reported in CNKI, so the references are less. In addition, it needs wisdom and strategy to make all the students insist on the English skills training and platform resource construction needs time and effort, it still call for strategy to encourage the students to involve in it.

\section{THE THEORETICAL BASE OF THE STUDY}

\section{A. Schematic theory in language training}

With the open educational concept and efficiencycentered thought, the study makes an application of personal Web pages to improve the students' language skills. In the application of the technology, when it comes to language training, schematic theory is based.Schematic theory is a theory which reflect recognitive laws, and according to the theory, the study emphasize the importance of designing thinking space for the students and creating simulated linguistic environment, at the same time give prominence to the main position of the students.

\section{B. The modern study view in activities organization for language training}

The English skills training patterning in the study takes the 
new constructivism and cooperative studying theory, and modern communicative theory as guides. In the study, the principals of leading role, cooperation, encouragement are followed, and the study gets down from providing good studying environment and the studying process, and the core is "the student development". The information transmission and communication between students and students, teachers and students goes through the study, which can uphold united and cooperative spirit and promote the students' active participation and practical experiences. The group members help each other, learn from each other, evaluate each other, which promote the process of the students' active exploration and participation. The study expects the constant improvement of the students' language skills in the multidimensional communicative activities.

\section{THE RESEARCH DEVICES OF THE STUDY}

The study aims to exploit the Web technology to innovatively enrich the ways, methods and devices of improvement of the students' English skills. the scientificity, practicability, efficiency and popularization of the study design should be checked in the practical study. In order to prove the value of the study, the study will make an argument from the following questions. The questions will be argued according to questionnaires, observations, visits, diaries, comparisons, and the analyses and summaries will be down through the device of materialization and quantization.

\section{A.. How often are the five platforms attached to the personal Web pages used?}

The popularity of the of the platforms can be mirrored to some degree from the application frequency of it, which connects to both the design and the contents. Collecting the clicking rate of the platforms can gain data directly. In addition, in order to the know the popularity among the students, questionnaires and interviews can be also done. It can be concluded from the materialized and quantified analysis of the data and work out improved measures.

\section{B. How much are the subjects' English skills improved?}

The efficiency will project in contrast. The study will make contrasts vertically and transversely: The English skills of the subjects and that of the non-subjects; the statement before the training and the effect after the training of the subjects. The Students' English skills can reflect whether the study is successful. The school activities, term examination and college English tests can all be used to make contrasts vertically and transversely. Sometimes the analyses needs the help of the software. The students' improvement of English skills lays a good foundation for class teaching. The teacher can check the students' autonomous study via Web pages through observing their class performance before and after the training.

\section{How do the teachers feel in the practice?}

Teachers and students are in opposition and at the same time they are related. What the students like can't be always done by the teachers, and certainly, the reverse is also true.
In a harmonious system, the teachers and the students can achieve what they want. Teachers should make selfless contribution for students. But getting half the results and even no results with double the effort will make the teachers wear out, it will be a heavy blow to their teaching enthusiasm. In order to make an awareness of the teachers' feeling, writing diaries and communications can work much.

\section{Conclusion}

The present study is in progression. Now it is liked by the students, but the proof materials haven't made. However the expected effects are in three aspects: The English skills of subjects are improved much; the original application cases of Web technology and Language skill training resources online are formed; the results of the study can be shared and discussed with the fraternity. With the progress of the study, the research will offer further report.

\section{REFERENCES}

[1] Wang Feng, Li Xiaoming. The Development of Online Technology Cause the Reformation of Teaching Mode[J]. Vocational and Technical Education, Aug. 2001, ISSN1008-3219, CN:22.1019/G4.

[2] Wang Yaming,Guo Huiling,Li Ziyang.Improve the Educational Level and Teaching Quality by Using Modern Educational Technology[J].The Journal Northeast Agricultural University(Social Science), Mar. 2006

[3] Wen Jun, Li Yanglong. The Foreign Language Teaching Research under the Modern LinguisticEnvironment[C]. Beijing: The Foreign Language Teaching and Research Publishing House,2001. pp. 119-133

[4] H. D. Brown. Principles of Language Learning and Teaching[M]. Beijing: The Foreign Language Teaching and Research Publishing House, 2001. pp.114-124

[5] H. G. Widdowson. Aspects of Language Teaching[M]. Shanghai: Shanghai foreign Language Education Publishing House, 2001, pp.127-146

[6] Shen Houkun. "The schematic theory and the research of English reading teaching" in Laws research for the improvement of teaching------College English Teaching Research[M]. Shanghai: Shanghai foreign Language Education Publishing House,2002. pp.239-244

[7] Xia Jimei. The Theory and Practice of Modern Foreign Language Course Design[M]. Shanghai: Shanghai foreign Language Education Publishing House, 2003. pp.1-1

[8] Bi Huiying, "On Interactive EFL Teaching Based on Web-based Platform," Proc. IEEE Symp. Robotics and Applications (ISRA),

IEEE Press, June. 2012, pp. 68-71, ISBN:978-1-4673-2206-5

[9] Zhang Zhijun and Wang Zushan, "Non-teacher Factors May Affect 
Teaching Evaluation from Students," Proc. IEEE Symp. Robotics and Applications (ISRA), IEEE Press, June. 2012, pp. 89-93, ISBN:978-14673-2206-5

[10] Pan Heng and He Pan, "Research and Practice on the Prefabricated Language Assisted by the Computers in College Foreign Langguage
Teaching" Proc. IEEE Symp. Robotics and Applications (ISRA), IEEE Press, June. 2012, pp. 61-65, ISBN:978-1-4673-2206-5 